\title{
A potential antiviral and food-derived healthy ingredient: Resveratrol
}

\author{
Ayla ARSLANER ${ }^{\circledR}$, Zehra TÜRKOĞLU®i
}

Cite this article as:

Arslaner, A., Türkoğlu, Z. (2021). A potential antiviral and food-derived healty ingredient: Resveratrol. Food and Health, 7(1), 54-63. https://doi.org/10.3153/FH21007

Bayburt University, Engineering Faculty, Food Engineering Department, Bayburt, Turkey,

ORCID IDs of the authors: A.A. 0000-0002-2777-9697 Z.T. 0000-0002-6449-5669

Submitted: 27.05 .2020

Revision requested: 30.09 .2020

Last revision received: 05.10 .2020

Accepted: 05.10 .2020

Published online: 09.12 .2020

Correspondence: Ayla ARSLANER

E-mail: aylaarslaner@bayburt.edu.tr

\begin{abstract}
Polyphenols are the secondary metabolites of plants and has an important role in human nutrition as the leading antioxidants. According to the carbon number-based classification of polyphenols, resveratrol is a natural polyphenol in the stilbene group with antioxidant and anticarcinogenic effects. Its beneficial effects on cardiovascular diseases have also been reported. It was first identified in 1940 and has recently gained importance especially in medicine and pharmacy. Researchers have carried out various studies on resveratrol and its time-honored use in traditional eastern medicine has been reported. Resveratrol is a food ingredient that has the potential to be used in the treatment of various diseases, but also has antiviral effects. The study focuses on resveratrol's physical and chemical properties, effects on health, antiviral effects and use in foods as a functional component.
\end{abstract}

Keywords: Resveratrol, Food, Health, Nutrition, Anti-viral

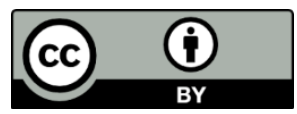

(C) 2021 The Author(s)

Available online at http://jfhs.scientificwebjournals.com 


\section{Introduction}

When facing a stress factor, plants synthesize a type of secondary metabolite with low molecular weight called phytoalexin as a defense mechanism. Trans-resveratrol is a polyphenolic phytoalexin from the stilbene group (Fremont, 1999). Polyphenols are secondary metabolites of plants and the most common antioxidants in human nutrition (Bravo, 1998; Emirdağ, 2014). Resveratrol is in the stilbene group according to the carbon number-based classification of polyphenols (; Athar et al., 2007). It is a natural polyphenol with reported antimicrobial, antioxidant and anticarcinogenic effects in addition to its beneficial effect on cardiovascular diseases; it joins the structure of various plants, is formed by the bonding of two aromatic rings with the methylene bond, contains three hydroxyl groups and can be found both in cis and trans configurations (Athar et al., 2007; Tokuşoğlu et al., 2005). It was first identified in 1940 in the roots of white hellebore and then, was found in the roots of Polygonum cuspidatum, also known as Kojo-kon in Japan. It was identified in the leaf epidermis and pericarp of grape berries in 1976 (Shishodia and Aggarwal, 2006). The study focuses on resveratrol's physical and chemical properties, effects on health, antiviral effects and use in foods as a functional component.

\section{The Physical and Chemical Properties of Resveratrol}

Many beneficial components such as antioxidants and phenolic substances in the structure of foods have biological regulatory roles, protective and nutritional properties in our body. During the metabolism of nutrients in our body, free radicals and other reactive oxygen species (ROS), also called toxins, are released. Free radicals are chemical structures containing one or more unpaired electrons in their outer orbitals. These structures lead to oxidation in our body, resulting in diseases and aging. Antioxidants neutralize free radicals by maintaining their own electrons in order to reduce the formed ROS and maintain their stability (Lobo et al., 2010). Antioxidants are secondary metabolites that can be produced spontaneously in the body or can be taken from the outside, usually through plants or synthetic drugs. Antioxidants help prevent or treat diseases as well as increase body resistance by reducing the effects of free radicals or altering their structure. Antioxidant activity, which is a measure of how much of the free radicals can be inactivated by antioxidants, can therefore be defined as free radical capture capacity (Kumarasamy et al., 2007).

Antioxidants are used to increase body resistance and protect human health, as well as to extend the shelf life of nutrients. Synthetic antioxidants are mainly used to extend the shelf life of nutrients in industrial processes. Today, BHA and BHT are used as synthetic antioxidants in many countries. Daily intake is reported by both Joint FAO/WHO Expert Committee on Food Additives (JECFA) and Commission of the European Communities as $0.5 \mathrm{mg} / \mathrm{kg}$ for BHA (EFSA, 2011) and JECFA allocated an ADI of $0-0.3 \mathrm{mg} / \mathrm{kg}$ bw/day for BHT (EFSA, 2012). Meanwhile, it has also been reported that the amount of consumption of antioxidants may be higher than specified and may cause liver and carcinogenic effects (Fremont, 1999). Synthetic forms of antioxidants are not preferred due to their toxic potential and interest in phenolic compounds with natural antioxidant properties increases day by day.

Polyphenols are the secondary metabolites of plants and has an important role in human nutrition as the leading antioxidants. According to the carbon number-based classification of polyphenols, resveratrol formed by connecting two aromatic rings with methylene bond; containing 3 hydroxy groups, available in cis and trans configurations is a natural polyphenol in the stilbene group. Resveratrol, which is found in the structure of many plant species, has been reported to have antimicrobial, antioxidant, anticarcinogenic effects and cardiovascular diseases decreasing effect (Tokuşoğlu et al., 2005; Lobo et al., 2010). Table 1 shows the chemical and physical properties of resveratrol.

Table 1. Physical and chemical properties of resveratrol (Haneke, 2002)

\begin{tabular}{|l|l|}
\hline Molecular Formula & $\mathrm{C}_{14} \mathrm{H}_{12} \mathrm{O}_{3}$ \\
\hline Structural Formula & \\
\hline Systematic Name & $\begin{array}{l}\text { 5-[(E)-2-(4-hidroxyphenyl)-ethenyl] } \\
\text { benzene-1,3-diol }\end{array}$ \\
\hline Other Names & $\begin{array}{l}\text { Trans-resveratrol } \\
\text { Trans-3,5,4'-trihydrozystilbene } \\
\text { 3,4',5-stilbenetriol } \\
\text { (E)-5- (p-hydroxy styryl) resorcinol } \\
3,5,4 '-\text { trihydroxy-cis-stilbene } \\
3,5,4^{\prime} \text {-trihydroxy-trans-stilbene }\end{array}$ \\
\hline Molecular Weight & 228.25 g/mol \\
\hline Boiling Point & 253 -255 ${ }^{\circ} \mathrm{C}$ \\
\hline Physical Structure & White - Solid \\
\hline Solubility & $\begin{array}{l}\text { Easily dissolves in water, methanol } \\
\text { and acetone. }\end{array}$ \\
\hline
\end{tabular}


Resveratrol is available in cis and trans isomers or glycolyzed form. It is mostly in glycolyzed (3-O-D-glucoside) form in plants. Glycolysis protects resveratrol from oxidative degradation (Athar et al., 2007). Glycolyzed resveratrol is very stable and water-soluble, easily and highly absorbed from the gastrointestinal tract. After absorption, it is metabolized in the liver to trans-resveratrol-3-O-glucuronite and trans resveratrol- 3-O-sulphate (Signorelli and Ghidoni, 2005). In vivo studies have shown that in healthy people, resveratrol is me- tabolized to the 3 and 4'-O-sulfate and 3-O-glucuronide conjugates less than 2 hours after consumption (Sing et al., 2015).

Resveratrol is formed by the combination of 3 molecules of CoA and 1 molecule of 4-cuamoryl CoA. Here, it is important that the enzyme needed for the synthesis of resveratrol is not normally active and activated when the plant is faced with a stress factor (Soleas et al., 1997). Figure 1 shows the biosynthesis of resveratrol.
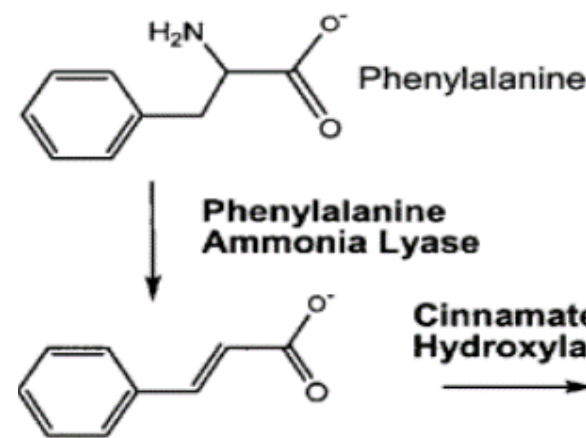

Cinnamic acid

Cinnamate-4Hydroxylase

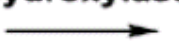<smiles>NC(Cc1ccc(O)cc1)C(=O)[O-]</smiles>

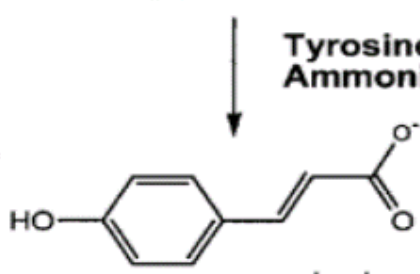

p-hydroxycinnamic acid

Coumaroyl CoA Ligase

3<smiles>O=C(O)CC(=O)SC(=O)[O-]</smiles>

Malonyl CoA<smiles>CC(C)OC(=O)C=Cc1ccc(O)cc1</smiles>

Coumaroyl CoA

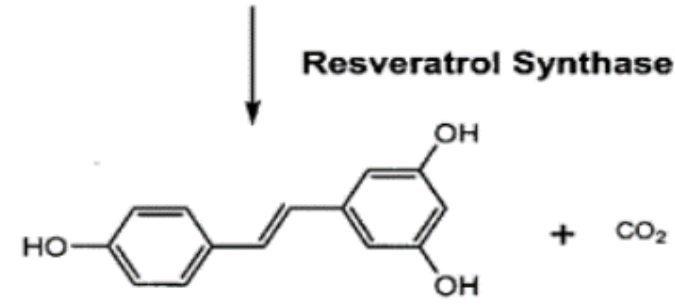

Resveratrol (3, 4', 5-trihydroxystilbene)

Figure 1. Resveratrol biosynthesis from phenylalanine (Becker et al. 2003, Huang et al. 2007) 


\section{The Sources of Resveratrol}

Resveratrol is a secondary metabolite synthesized as a defense compound against various external factors and found most abundantly in the product obtained by the drying of the roots of Polygonum cuspidatum (Konjo-Kon or Itadori tea), a plant traditionally used in Japan and China (Nonomura et al., 1963; Savouret and Quesne, 2002). Vastano et al. (2000) reported that Polygonum cuspidatum consist 2960-3770 ppm resveratrol. Chen et al. (2013) mentioned that the root contains a much higher level of resveratrol than the stem and leaf, and it is accumulated in its highest level in October. Prince Edward Island, Canada-grown knotweed contains similar levels of resveratrol and polydatin compared to Chinese samples collected in the month of October.

In studies on resveratrol and its derivative stilbene compounds, mainly grape and grape products (Concenco et al., 2019). Mnari et al. (2016) reported that resveratrol contents of Tunisian raisins varieties in range of $0.02-0.12 \mathrm{mg} / \mathrm{g}$ dry weight. Lyons et al (2003) indicated that wild blueberry and bilberries might serve as another dietary source of resveratrol. Shrikanta et al. (2015) stated that some of the less consumed fruits such as mulberry, jamun and jackfruit are rich in resveratrol and can be processed by processing into functional drinks. Values of resveratrol in European plum (Prunus domestica) cultivars detected average $1.0 \mu \mathrm{g} / 1 \mathrm{~g}$ (Sebasti ${ }^{\prime}$ et al., 2012).

In addition, resveratrol has been identified in black chocolate and cocoa liquor and hops used in beer making (Athar et al., 2007). Salvador et al. (2018) observed the highest contents of trans-resveratrol in alkalized cocoa powder and natural cocoa powder $(13.53 \mu \mathrm{g} / \mathrm{kg}$ and $11.40 \mu \mathrm{g} / \mathrm{kg})$ respectively.

Some studies have shown that resveratrol glucoside was the major form available in most vegetable and the content of resveratrol forms in different varieties and regions were different (Peng et al., 2005), also the content varying with seasonal, geographical, and environmental factors (Kurita et al., 2013). Some of specific vegetable foods such as celery (originated in West China, $783.29 \mu \mathrm{g} / 100 \mathrm{~g}$ ), red radish (North China, $194.4 \mu \mathrm{g} / 100 \mathrm{~g}$ ), Coprinus comatus (Midland China, $573.74 \mu \mathrm{g} / 100 \mathrm{~g}$ ) have been reported to be important sources of resveratrol (Peng et al., 2005). Sebastia et al. (2017) announced that trans-resveratrol contents varied from 20 $\mu \mathrm{g} / 100 \mathrm{~g}$ (tomato and strawberry) to $300 \mu \mathrm{g} / 100 \mathrm{~g}$ in dates (Phoenix dactylifera L.).

Some of the wild and ornamental plant species, edible mushrooms have also been reported to be an important source of resveratrol. Average trans-resveratrol amounts have been determined $1.07 \mu \mathrm{g} / \mathrm{g}$ and $0.7960 \mu \mathrm{g} / \mathrm{g}$ in Solanum americanum ripe fruit pulp and peel, respectively (Vagula et al., 2016). Akyüz et al. (2012) detected resveratrol in some edible mushroom samples in the range of $0.25-0.75 \mu \mathrm{g} / \mathrm{g}$.

Alkan (2007) pointed out that grape skins, which are rich in resveratrol amount, which are separated as waste during the production of molasses, can be evaluated in this direction. Silva et al. (2014) studied guava and Surinam cherry byproduct and concluded that the content of resveratrol in the byproducts $25.67 \mathrm{mg} / 100 \mathrm{~g}$ and $112.51 \mathrm{mg} / 100 \mathrm{~g}$ dry basis, respectively. The researchers underlined the nutraceutical potential and future application in the food industry of the agrifood byproducts (Silva et al., 2014; Annunziata et al., 2018).

\section{The Effects of Resveratrol on Health}

Free radicals are chemical structures that contain one or more unpaired electrons in their outer orbitals. Although the reactive chemical compounds are formed in organisms due to oxidation and reduction reactions, they can also be formed due to external factors such as radiation, UV lights, air pollution, and combustion products of fossil fuels, some insecticides, pesticides, viruses, infections and drugs. In the case where they are not eliminated in an organism, free radicals cause pathological disorders and aging. Antioxidants reduces the effects of free radicals in the body and foods and/or alter their structures so that the oxidation reactions are significantly inhibited or delayed (Shahidi and Ambigaipalan, 2015).

Various studies have emphasized the cardiovascular protective, antithrombotic, antioxidant, anti-inflammatory, blood sugar reducing and anticancer activities of resveratrol. It naturally has two different isomeric forms and its trans form has been reported to be more important and stable and, thus, more widely used in studies. Trans-resveratrol has different biological properties and has been reported to have stronger antioxidant and cardioprotective effects (Gliemann et al., 2016). Preventing the cancer development in organisms may be possible with sufficient levels of optimized analogs of the resveratrol molecule and increased stability and bioavailability in organisms (Kiskova et al., 2020).

Recent studies have shown that resveratrol had protective effects against neurodegenerative diseases such as Alzheimer's disease and obesity in addition to its effectiveness in the treatment of osteoporosis in postmenopausal women with low breast cancer risk (Kuršvietienè et al., 2016). Resveratrol inhibited lipid peroxidase in linoleic acid emulsion at a higher rate $(89.1 \%)$ when compared with synthetic antioxidants at the same concentration (Gülçin, 2010). Its antiaging effect and enhancing effect on insulin sensitivity, the enzymatic activity of the sirtuin gene (SIRT 1-7) and mitochondria number 
were associated with its antioxidant activity (Kındır and Güvenç, 2010).

The current literature suggests that resveratrol prevents cancer through various mechanisms including anti-proliferative, anti-inflammatory and anti-angiogenesis mechanisms by initiating apoptosis (Singh et al., 2015). Apoptosis induction is the key mechanism in the inhibition of the formation of many tumors. Resveratrol induces p53-mediated apoptosis in cancer cells, including prostate cancer, colon cancer and breast cancer (Yu et al., 2012).

Resveratrol may inhibit enzymatic activity in another mechanism through which resveratrol is believed to inhibit the development of cancer cells. Cyclooxygenase and decarboxylase are included in the cancer-causing enzyme groups. Epidemiological studies have shown that long-term cyclooxygenase inhibition reduced the development of various cancer types and cancer caused by the enzyme was prevented with the deletion of the cyclooxygenase-II (COX2)-coding gene (Yu et al., 2012). Its effect on tumor formation stems from its inhibitory effect on the antimutagens and free radicals in animal models and antioxidant properties. The inhibition of COX-1 reduces tumor progression and resveratrol have been reported to substantially inhibit the COX-1 enzyme (Savouret and Quesne, 2002).

Although French people consume fat and cholesterol-rich foods, they are $40 \%$ less likely to develop cardiovascular diseases than the rest of Europe. This is associated with the consumption of resveratrol in red wine and referred to as the "French Paradox" (Kopp, 1998; Yu et al., 2012). Plaque formation in veins leads to thrombosis and consequently embolism. The main cause of cardiovascular diseases is embolism. Atherosclerosis is a result of the impairment of the reactions between the normal cell elements of the artery-related wall and blood. Atherosclerosis can be prevented by consuming anti-atherogenic foods. As a polyphenol, resveratrol has a good protective effect on different parts of atherosclerosis (Das and Da, 2007). The protective mechanism of resveratrol against cardiovascular diseases was suggested to operate by blocking the thrombocyte aggregation and reducing cholesterol through its anti-inflammatory effects (Keskin et al., 2009).

Alzheimer's disease (AD) is not only a growing health issue but also a social and economic load. AD occurs due to the accumulation of $\beta$ - amyloid plaques on the nerve cells in brain and its cause is still not known. Its severity increases over years and currently, there is not a cure for $\mathrm{AD}$ (Granzatto and Zatta, 2014). Of the affected individuals, $15 \%$ are in the $65-74$ age group and $44 \%$ are in the $75-84$ age group. Aging and genetic disposition are classically considered the unavoidable risk factors for $\mathrm{AD}$. On the other hand, environmental factors, insulin resistance, obesity and metabolic syndromes are avoidable risk factors for AD. Factors such as regular physical activity, Mediterranean diet (fruits, vegetables, hazelnut, beans, olive oil, etc.), calorie restriction and maintaining the ideal body weight (or intermittent fasting), reducing smoking, controlling diseases such as diabetes, hypertension, and lifelong learning can delay or prevent aging-related cognitive decline (Sawda et al., 2017). Preclinical studies support the potential role of resveratrol in the treatment and prevention of neurodegenerative diseases such as Huntington's disease, Parkinson disease and AD (Sun et al., 2010). Resveratrol can protect against neurodegenerative diseases by eliminating reactive oxygen species (ROS), hydrogen peroxide and free radicals, NO, A $\beta$ and other intra- and extracellular toxins through the SIRT1 activation mechanism (Graff et al., 2013).

Resveratrol is a food ingredient that has the potential to be used in the treatment of various diseases, but also displays antimicrobial activity against a surprisingly wide range of bacterial, viral and fungal species (Vestergaard and Ingmer, 2019). In 1976, one of the first studies showing the antiviral activity of polyphenols was carried out and it was found that especially the grape juice phenolic components separated by a membrane filtration showed a preventive activity against the poliovirus (Annunziata et al., 2018).

It has been stated that in combating many drugs-resistant viruses (HSV-1, HSV-2 etc.) natural food-derived matrices such as grape pulp rich in resveratrol and other polyphenols, which have no side-effect, can be evaluated (Annunziata et al., 2018).

Antiviral mechanisms and effects of resveratrol have been reported to be widely investigated in such as influenza virus, herpes simplex virus, respiratory syncytial virus, human immunodeficiency virus (HIV), hepatitis $\mathrm{C}$ virus and multiple sclerosis (MS). Most of these studies have announced that the progression of the disease and recession of the viral infections after administration of resveratrol (except to MS and hepatitis C). Antiviral mechanisms of resveratrol arise through inhibition of viral protein synthesis, inhibition of various transcription and signaling pathways, and inhibition of viral associated gene expressions (Annunziata et al., 2018).

Mohd et al. (2019) suggested that resveratrol exhibited direct virucidal activity against Zika virus (ZIKV) and possessed anti-ZIKV replication properties, highlighting the need for further exploration of resveratrol as a potential antiviral molecule against ZIKV infection. 
Eighty-Six percent of the genetic sequence of SARS-CoV is the same as SARS-CoV-2, the virus responsible for the global pandemic caused by infectious disease COVID-19 (Chan et al., 2020). The angiotensin converting enzyme-2 (ACE2) cellular receptor is responsible for the pathogenesis of severe acute respiratory syndrome coronavirus 2 (SARS-CoV-2), thus affecting the entrance and clearance of the virus (Zhu et al., 2020). Overall, ACE2 activity is protective against SARS-CoV pathogenesis. Recent research suggests that the nutrients in our daily diet may affect the expression and function of the ACE2 gene, and resveratrol has the potential to contribute to ACE2 activity. Therefore, adding resveratrol to the diet can help reduce the harmful effects of high-fat diets on ACE2 gene expression. It has also been suggested to be used in regulating diet strategies in order to reduce disease severity in COVID-19 pandemic (Horne and Vohl, 2020).

The bioavailability of resveratrol after ingestion, the potential of dietary or direct intake in humans and animals, in the treatment of viral infections should be explored in more detail.

\section{The Use of Resveratrol as a Functional Component in Foods}

In order to increase product functionality, studies in which resveratrol is added to the food matrix are not common. Resveratrol is found small quantities in the diet; any protective effect of this molecule is unlikely at normal nutritional intakes (Manach et al., 2004). Therefore, a detailed investigation of the effects of resveratrol on humans and determination of how the resveratrol concentration especially in foods and beverages that are biologically related to resveratrol can be increased are needed (Pastor et al., 2019). It has been reported that encapsulation of resveratrol, which has a higher solubility in food-grade oils, can be used to improve its waterdispersibility, chemical stability, and bioavailability, thus it can be incorporate resveratrol into aqueous based products that have lower fat and calorie contents, such as some beverages, yogurts, sauces, dressings, and desserts. (DavidovPardo and McClements, 2014).

Acar (2011) investigated the effects of the interaction between resveratrol and milk proteins on the Maillard reaction and found that around percentage 80 of resveratrol crosslinked with milk proteins, but the concentration of resveratrol did not have a significant effect on the Maillard reaction.

Emirdağ (2014) investigated the effects of the interaction between resveratrol and milk proteins on the textural properties and water-holding capacity of yogurt, which are among important parameters in yogurt production. To determine the interaction of resveratrol with milk proteins and how the interaction occurs, resveratrol was analyzed with RP-HPLC and the results showed that around $85 \%$ of resveratrol interacted with milk proteins.

In a pilot study investigating the addition of resveratrol instead of sulphur dioxide, an antioxidant, during wine production, Pastor et al. (2015) reported that the addition of two different concentrations of resveratrol $(150 \mathrm{mg} / \mathrm{L}$ and $300 \mathrm{mg} / \mathrm{L})$ did not have any negative effect on the organoleptic and sensory properties of the products. Researchers have also suggested that the negative effects of sulphur dioxide on health can be prevented with the addition of resveratrol.

In their study on the production of a functional yogurt that is suitable for the consumption of all age groups, Türkoğlu (2019) added $25 \mathrm{mg} / 100 \mathrm{~g}, 50 \mathrm{mg} / 100 \mathrm{~g}, 75 \mathrm{mg} / 100 \mathrm{~g}$ and $100 \mathrm{mg} / \mathrm{g}$ resveratrol to the set-type traditional yogurts produced with Lactobacillus bulgaricus + Streptococcus thermophilus and probiotic yogurts containing Lb. bulgaricus + $S$. thermophilus: Lb. acidophilus (1:1). The results of the study revealed that, considering all parameters in terms of the physicochemical and microbiological properties and sensory scores at the end of day $28,50 \mathrm{mg} / 100 \mathrm{~g}$ resveratrol-added traditional and probiotic yogurts were new functional products suitable for consumption.

Yu et al. (2020), investigated potential of resveratrol in mitigating advanced glycation end-products formed in baked milk and baked yogurt and the results of the research provided a promising strategy for inhibiting the AGEs formed in baked milk and baked yogurt with the addition of a proper concentration of resveratrol.

In the future, the number of studies investigating the enrichment of products frequently consumed in the daily diet with the addition of resveratrol may increase.

\section{Conclusions}

As a natural polyphenol, resveratrol has various biochemical and physiological effects such as anti-inflammatory, antioxidative, antiproliferative and chemopreventive effects. Recent studies have shown its positive effects especially on cardiovascular diseases, cancer, type 2 diabetes and neurological disorders. In addition, studies reported that resveratrol has shown a high antiviral potential in both human and animal viral infections. The bioavailability of resveratrol after ingestion, the potential of dietary or direct intake in humans and animals, in the treatment of viral infections should be explored in more detail. It appears that more than the amount naturally found in food is needed to provide the expected benefits from resveratrol. Moreover, variety, region, seasonal, geographical, and environmental conditions have affected resveratrol contents of food. For this reason, it is often not 
possible to consume adequate resveratrol in the diet. Agricultural food waste and byproducts should be investigated in terms of resveratrol potential. As our understanding of the positive effects of resveratrol on health grows, the antioxidant will continue to be the subject of many scientific studies.

\section{Compliance with Ethical Standard}

Conflict of interests: The authors declare that for this article they have no actual, potential or perceived the conflict of interests.

Ethics committee approval: The authors declare that this study does not require ethical permission.

Funding disclosure: -

Acknowledgments: -

Disclosure: A part of this research was presented as oral and published form at the 3rd International Conference Advanced Engineering Technologies (ICADET'19), 19-21 September 2019, Bayburt, Turkey.

\section{References}

Acar, F. (2011). Effects of resveratrol on milk proteins and Millard reaction. Hacetepe University, M.Sc. Thesis, Department of Food Engineering, Graduate School of Natural and Applied Sciences, Ankara-Turkey.

Akyüz, M., Onganer, A.N., Erecevit, P. and Kirbag, S. (2012). Flavonoid contents and 2,2-diphenyl-1-picrylhydrazyl radical scavenging activity of some edible mushrooms from Turkey: A. bisporus and Pleurotus spp. Current Topics in Nutraceutical Research, 10(2), 133-136.

Alkan, R. (2007). Doğal bitki antibiyotiği: Resveratrol. Glda, 32 (5), 259-262.

https://dergipark.org.tr/en/pub/gida/issue/6814/91567

Annunziata, G., Maisto, M., Schisano, C., Ciampaglia, R., Narciso, V., Tenore, G.C. Novellino, E. (2018). Resveratrol as a novel anti-herpes simplex virus nutraceutical agent: An Overview, Viruses, 10(9), 1-10.

https://doi.org/10.3390/v10090473

Athar, M., Back, J.H., Tang, X., Kim, K.H., Kopelovich, L., Bickers, D.R., Kim, A.L. (2007). Resveratrol: A review of preclinical studies for human cancer prevention. Toxicology and Applied Pharmacology, 224(3), 274-283.

https://doi.org/10.1016/j.taap.2006.12.025
Becker, V.W., Armstrong, G.O., Merwe, M.J., Lambrechts, M.G., Vivier, M.A., Pretorius, I.S. (2003). Metabolic engineering of Saccharomyces cerevisiae for the synthesis of the wine-related antioxidant resveratrol, FEMS Yeast Research, 4, 79-85.

https://doi.org/10.1016/S1567-1356(03)00157-0

Bravo, L. (1998). Polyphenols: Chemistry, dietary sources, metabolism and nutritional significance. Nutrition Reviews, 56 (11), 317-333.

https://doi.org/10.1111/j.1753-4887.1998.tb01670.x

Chan, J.W. F., Kok, K.H., Zhu, Z., Chu, H., To, K.K.W., Yuan, S. Yuen, K.Y. (2020). Genomic characterization of the 2019 novel human-pathogenic coronavirus isolated from a patient with atypical pneumonia after visiting Wuhan. Emerging Microbes \& Infections, 9, 221-236.

https://doi.org/10.1080/22221751.2020.1719902

Chen, H., Tuck, T., Ji, X., Zhou, X., Kelly, G., Cuerrier, A., Zhang, J. (2013). Quality assessment of Japanese knotweed (Fallopia japonica) grown on Prince Edward Island as a source of resveratrol. Journal of Agricultural and Food Chemistry, 61, 6383-6392.

https://doi.org/10.1021/jf4019239

Concenco F.I.G.R., Brotto, G.F., Nora, L. (2019). Grape wine and juice: Comparison on resveratrol levels. International Journal of Advanced Engineering Research and Science (IJAERS), 6(4), 378-386.

https://dx.doi.org/10.22161/ijaers.6.4.44

Das, S., Das, D.K. (2007). Resveratrol: A therapeutic promise for cardiovascular diseases. Recent Patents on Cardiovascular Drug Discovery, 2(2), 133-138.

https://doi.org/10.2174/157489007780832560

Davidov-Pardo, G., McClements, D.J. (2014). Resveratrol encapsulation: Designing delivery systems to overcome solubility, stability and bioavailability issues. Trends in Food Science \& Technology, 38(2), 88-103.

https://doi.org/10.1016/j.tifs.2014.05.003

EFSA (2011). EFSA Panel on Food Additives and Nutrient Sources added to Food (ANS); Scientific Opinion on the reevaluation of butylated hydroxyanisole-BHA (E 320) as a food additive. EFSA Journal, 9(10), 2392, 1-49.

https://doi:10.2903/j.efsa.2011.2392 
EFSA (2012). EFSA Panel on Food Additives and Nutrient Sources added to Food (ANS); Scientific Opinion on the reevaluation of Butylated hydroxytoluene BHT (E 321) as a food additive. EFSA Journal, 10(3), 2588, 1-43.

https://doi:10.2903/j.efsa.2012.2588

Emirda $\breve{g}$ H. (2014). Resveratrolün yoğurtta tekstürel nitelikleri geliştirme olanakları. Hacettepe University, Graduate School of Natural and Applied Sciences, Master Thesis, Ankara, Turkey.

Fremont, L. (1999). Biological effect of resveratrol. Life Sciences, 66(8), 663-673.

https://doi.org/10.1016/s0024-3205(99)00410-5

Gliemann, L., Nyberg, M., Hellsten, Y. (2016). Effects of exercise training and resveratrol on vascular health in aging. Free Radical Biology and Medicine, 98, 165-176.

https://doi.org/10.1016/j.freeradbiomed.2016.03.037

Graff, J., Khan, M., Samiei, A., Gao, J., Ota, K.T., Rei, D., Tsai, L.H. (2013). A dietary regimen of caloric restriction or pharmacological activation of SIRT1 to delay the one set of neurodegenerations. Journal of Neuroscience, 33(21), 89518960. https://doi.org/10.1523/JNEUROSCI.5657-12.2013

Granzatto, A., Zatta, P. (2014). Resveratrol and Alzheimer's disease: message in a bottle a red wine and cognition. Frontiers in Aging Neuroscience, 6(95), 1-7.

https://doi.org/10.3389/fnagi.2014.00095

Gülçin, İ. (2010). Antioxidant properties of resveratrol: A structure-activity insight. Innovative Food Science and Emerging Technologies, 11(1), 210-218.

https://doi.org/10.1016/j.ifset.2009.07.002

Haneke, K.E. (2002). Review of toxicological literature, trans-resveratrol (501-36-0), Integrated Laboratory Systems, P.O. Box 13501, Research Triangle Park, North Carolina 27709, Contact No: N01-ES-65402.

Hang, Y., Zhong, Q., Guo, Y., Xie, Y., Cheng, Y., Yao, W. (2020). Potential of resveratrol in mitigating advanced glycation end-products formed in baked milk and baked yogurt. Food Research International, 133, 109191.

https://doi.org/10.1016/i.foodres.2020.109191

Horne J.R., Vohl, M.C. (2020). Biological plausibility for interactions between dietary fat, resveratrol, ACE2, and SARS-CoV illness severity. American Journal of Physiology Endocrinology and Metabolism, 318(5), 830-833. https://doi.org/10.1152/ajpendo.00150.2020

Huang, L., Lixuan, L., Zhixiong, Z., Quinn, Q. (2007). Method for the production of resveratrol in a recombinant bacterial host cell, United States Patent, vol. 20070031951.

Keskin, N., Noyan, T., Kunter, B. (2009). Resveratrol ile üzümden gelen sağlık. Türkiye Klinikleri Journal of Medical Science, 29(5), 1273-1279.

Kındır, Ö., Güvenç, A. (2010). Investigation of process parameters on recycling of black grape pulp as antioxidant source. M.Sc. Thesis. Department of Chemical Engineering, Graduate School of Natural and Applied Sciences, Ankara University, Ankara, Turkey.

Kiskova, T., Kubatka, P., Büsselberg, D., Kassayova, M. (2020). The Plant-Derived Compound Resveratrol in Brain Cancer: A Review. Biomolecules, 10 (161), 1-19.

https://doi:10.3390/biom10010161

Kopp, P. (1998). Resveratrol a phytoestrogen found in red wine a possible explanation for the conundrum of the 'French Paradox'? European Journal of Endocrinology, 138/6, 619620.

https://doi.org/10.1530/eje.0.1380619

Kumarasamy, Y., Byres, M., Cox, P.J., Jaspars, M., Nahar, L., Sarker, S.D. (2007). Screening seeds of some Scottish plants for free radical scavenging activity. Phytotherapy Research, 21, 615-621.

https://doi.org/10.1002/ptr

Kurita, S., Kashiwagi, T., Ebisu, T., Shimamura, T., Ukeda, H. (2014). Content of resveratrol and glycoside and its contribution to the antioxidative capacity of Polygonum cuspidatum (Itadori) harvested in Kochi. Bioscience, Biotechnology, and Biochemistry, 78(3), 499-502.

https://doi.org/10.1080/09168451.2014.890032

Kuršvietienė, L., Stanevičienė, I., Mongirdienė, A., Bernatoniené, J. (2016). Multiplicity of effects and health benefits of resveratrol. Medicina, 52(3), 148-155.

https://doi.org/10.1016/j.medici.2016.03.003

Lobo, V., Patil, A., Phatak, A., Chandra, N. (2010). Free radicals, antioxidants and functional foods: Impact on human health. Pharmacognosy Reviews, 4 (8), 118-126. https://doi.org/10.4103/0973-7847.70902 
Lyons, M.M., Yu, C., Toma, R.B., Cho, S.Y., Reiboldt, W., Lee, J., Van Breemen, R.B. (2003). Resveratrol in raw and baked blueberries and bilberries. Journal of Agricultural and Food Chemistry, 51 (20), 5867-5870.

https://doi.org/10.1021/jf034150f

Manach, C., Scalbert, A., Morand, C., Rémésy, C., Jime'nez, L. (2004). Polyphenols: food sources and bioavailability. American Society for Clinical Nutrition, 79, 727-47. https://doi.org/10.1093/ajen/79.5.727

Mnari, A.B., Harzallah, A., Amri, Z., Aguir, S.D., Hammami, M. (2016). Phytochemical content, antioxidant properties, and phenolic profile of Tunisian raisin varieties (Vitis Vinifera L.). International Journal of Food Properties, 19(3), 578-590.

http://dx.doi.org/10.1080/10942912.2015.1038720

Mohd, A., Zainal, N., Tan, K.K., AbuBakar, S. (2019). Resveratrol affects Zika virus replication in vitro. Scientific Reports, 9,14336, 1-11.

https://doi.org/10.1038/s41598-019-50674-3

Nonomura, S., Kanagawa, H., Makimoto, A. (1963). Chemical constituents of polygonaceous plants. I. Studies on the components of ko-jo-kon (Polygonum Cuspidatum SIEB et ZUCC). Yakugaku Zasshi, 83, 983-990.

https://doi.org/10.1248/yakushi1947.83.10988

Pastor, R.F., Gargantini, M.R., Murgo, M., Prieto, S., Manzano, H., Aruani, C., Quini, C.I., Covas, M.I., Iermoli, R.H. (2015). Enrichment of resveratrol in wine through a new vinification procedure. Journal of Life Sciences, 9, 327-333.

https://doi.org/10.17265/1934-7391/2015.07.005

Pastor, R.F., Restani, P., Di Lorenzo, C., Orgiu, F., Teissedre, P.L., Stockley, C., Ruf, J.C., Quini, C.I., Tejedor, N.G., Gargantini, R., Aruani, C., Prieto, S., Murgo, M., Videla, R., Penissi, A., Iermoli, R.H. (2019). Resveratrol, human health and winemaking perspectives. Critical Reviews in Food Science and Nutrition, 59(8), 12371255.

https://doi.org/10.1080/10408398.2017.140051759

Peng, X.L., Xu, J., Sun, X.F., Ying, C.J., Hao, L.P. (2015). Analysis of trans-resveratrol and trans-piceid in vegetable foods using high-performance liquid chromatography. International Journal of Food Sciences and Nutrition, 66(7), 729735.

https://doi.org/10.3109/09637486.2015.1088934
Salvador, I., Massarioli, A.P., Silva, A.P.S., Malaguetta, H., Melo, P.S., Alencar, S.M. (2018). Can we conserve trans-resveratrol content and antioxidant activity during industrial production of chocolate? Journal of the Science of Food and Agriculture, 99(1), 83-89.

https://doi.org/10.1002/jsfa.9146

Savouret, J.F., Quesne, M. (2002). Resveratrol and cancer: A review. Biomedicine \& Pharmacotherapy, 56(2), 84-87. https://doi.org/10.1016/S0753-3322(01)00158-5

Sawda, C., Moussa, C., Turner, R.S. (2017). Resveratrol for Alzheimer's disease. Annals of the New York Academy of Sciences, 1403(1), 142-149.

https://doi.org/10.1111/nyas.13431

Sebasti`a, N., Montoro, A., Manes, J., Soriano, J.M. (2012). A preliminary study of presence of resveratrol in skins and pulps of European and Japanese plum cultivars. Journal of the Science of Food and Agriculture, 92(12), 3091-3094.

https://doi.org/10.1002/jsfa.5759

Sebastia, N., Montoro, A., Leon, Z., Soriano, J.M. (2017). Searching trans-resveratrol in fruits and vegetables: a preliminary screening. Journal of Food Science and Technology, 54(3), 842-845.

https://doi.org/10.1007/s13197-016-2474-7

Shahidi, F., Ambigaipalan, P. (2015). Phenolics and polyphenolics in foods, beverages and spices: Antioxidant activity and health effects-A review. Journal of Functional Foods, 18, 820-897.

https://doi.org/10.1016/j.jff.2015.06.018

Shishodia, S., Aggarwal, B.B. (2006). Resveratrol: A polyphenol for all seasons. In: Aggarwal BB, Shishodia S (eds.): Resveratrol in Health and Disease, Boca Raton 2006, pp. 116.

https://doi.org/10.1201/9781420026474-1

Shrikanta, A., Kumar, A., Govindaswamy, V. (2015). Resveratrol content and antioxidant properties of underutilized fruits. Journal of Food Science and Technology, 52(1), 383-390.

https://doi.org/10.1007/s13197-013-0993-z

Signorelli, P., Ghidoni, R. (2005). Resveratrol as an anticancer nutrient: molecular basis, open questions and promises. Journal of Nutritional Biochemistry, 16(8), 449-466. https://doi.org/10.1016/j.jnutbio.2005.01.017 
Silva, L.M.R., Figueiredo, E.A.T., Ricardo, N., Vieira, I.G.P., Figueiredo, R.W., Brasil, I.M., Gomes, C.L. (2014). Quantification of bioactive compounds in pulps and by-products of tropical fruits from Brazil. Food Chemistry, 143, 398404.

http://dx.doi.org/10.1016/j.foodchem.2013.08.001

Singh, C.K., Nadiaye, M.A., Ahmad, N. (2015). Resveratrol and cancer: Challenges for clinical translation. Biochimica et Biophysica Acta (BBA) - Molecular Basis of Disease, 1852(6), 1178-1185.

https://doi.org/10.1016/j.bbadis.2014.11.004

Soleas, G.J., Daimandis, E.P., Goldbeng, D.M. (1997). Resveratrol: A molecule whose time has come? and Gone? Clinical Biochemistry, 30 (2), 91-113.

https://doi.org/10.1016/S0009-9120(96)00155-5

Sun, A.Y., Wang, Q., Simonyi, A., Sun, G.Y. (2010). Resveratrol as a therapeutic agent for neurodegenerative diseases. Molecular Neurobiology, 41, 375-383.

https://doi.org/10.1007/s12035-010-8111-y

Tokuşoğlu, Ö., Ünal, M.K., Yemis, F. (2005). Determination of the phytoalexin resveratrol (3,5,4'-trihydroxystilbene) in peanuts and pistachios by High Performance Liquid Chromatographic Diode Array (HPLC-DAD) and Gas Chromatography-mass Spectrometry (GC-MS). Journal of Agricultural Food Chemistry, 53(12), 5003-5009.

https://doi.org/10.1021/jf050496

Türkoğlu, Z. (2019). Resveratrol ilavesiyle üretilen probiyotik yoğurtların bazı kalite niteliklerinin belirlenmesi.
Bayburt University, M.Sc. Thesis, Department of Food Engineering, Graduate School of Natural and Applied Sciences, Bayburt-Turkey.

Vagula, J.M., Bertozzi, J., Castro, J.C., de Oliveira, C.C., Clemente, E., de Oliveira Santos Júnior, O., Visentainer, J.V. (2016). Determination of trans-resveratrol in Solanum americanum Mill. by HPLC. Natural Product Research, 30(19), 2230-2234.

https://doi.org/10.1080/14786419.2016.1149704

Vastano, B.C., Chen, Y., Zhu, N., Zhou, Z., Rosen, R.T. (2000). Isolation and identification of stilbenes in two varieties of Polygonum cuspidatum. Journal of Agricultural and Food Chemistry, 48(2), 253-256.

https://doi.org/10.1021/jf9909196

Vestergaard, M., Ingmer, H. (2019). Antibacterial and antifungal properties of resveratrol. International Journal of Antimicrobial Agents, 53(6), 716-723.

https://doi.org/10.1016/j.ijantimicag.2019.02.015

Yu, W., Fu, Y.C. Wang, W. (2012). Cellular and molecular effects of resveratrol in health and disease. Journal of Cellular Biochemistry, 113(3), 752-759.

https://doi.org/10.1002/jcb.23431

Zhu, N., Zhang, D., Wang, W., Li, X., Yang B., Song, J., Zhao, X. , Huang, B., Shi, W., Lu, R., Niu, P., Zhan, F., Ma, X., Wang, D., Xu, W., Wu, G., Gao, G.F., Tan, W. (2020). A novel coronavirus from patients with pneumonia in China, 2019. The New England Journal of Medicine, 382(8), 727-733.

https://doi.org/10.1056/NEJMoa2001017 